http://rev.med.panacea.unica.edu.pe

Rev méd panacea. 2013; 3(3): 87-88.

Recibido: 15 de Noviembre del 2013 | Aceptado: 15 de Diciembre del 2013 | Publicado: 31 de Diciembre del 2013

CONFLICTOS DE INTERÉS: NO DECLARADOS

ARTICULO ESPECIAL

\title{
Breve reseña histórica de la facultad de medicina de Ica*
}

\author{
Carlos Román-Ruíz ${ }^{1 a}$ \\ Facultad de Medicina. Universidad San Luis Gonzaga. Ica, Perú1 \\ Profesor principala
}

$\mathbf{E}^{\mathrm{n}}$ la ceremonia de las bodas de oro de la facultad de medicina de Ica (21 de junio del 2013) no se pudo dejar de mencionar algunos episodios históricos acontecidos en la facultad de medicina.

Las principales etapas históricas de nuestra facultad tienen un sitial muy especial, que sirve como base para nuestras determinaciones actuales y los rumbos futuros de la facultad de medicina.

\section{ETAPA DE PREMÉDICAS}

La facultad se inicia con Pre-medicas (1961 y 1962) en tres turnos (mañana tarde y noche), era obligatorio el curso premilitar.

En 1962 inseguridad futura para los estudiantes, la ley Nª12495 no especificaba facultad de medicina.

El Dr. Eduardo Caballero Escudero fue nombrado presidente de la comisión "Procreación de Facultad de Medicina", debido a su identificación con la facultad, además de su persistencia en las gestiones, sin mencionar el optimismo y la voluntad, que poseía.

\section{ETAPA DE LA FACULTAD DE MEDICINA}

El 21 de junio de 1963 con resolución $N^{\circ} 133$ se crea la facultad de medicina, asimismo, en consejo de facultad se nombra al Dr. Aníbal Casavilca Rubio como decano, el cual con mucha responsabilidad y dedicación supo velar por las necesidades de infraestructura, presupuesto y profesores, además, contó con el asesoramiento de funcionarios de la Organización Panamericana de la Salud en el desarrollo del plan de estudios.

\section{LOGROS}

- Organización de ciencias básicas, anatomía patológica y ciencias dinámicas.

- Centro detector del cáncer.

- Centro preventivo Mollendo.

- Fundación del club social deportivo de medicina "CLUBSDEM”, que participo en la "Copa Perú" y se mantuvo en el futbol profesional por varios años.

- Se firma un convenio (1965) entre el Hospital Departamental de Salud y la universidad. Sin embargo, un decreto supremo anula este convenio. La reacción fue una marcha a pie desde Ica a Lima, que duro ocho días, en la que solo se consiguen promesas, a un costo muy alto, la muerte de Victoria Astupiña y la fractura de columna de otro alumno, Víctor Luna.

- En respuesta, se realizo una huelga de hambre en el patio central de la ciudad, solo así se logró un "un nuevo convenio".

Además se logra:

- Concurso docente asistencial en el Hospital Regional (1967).

* Discurso del Dr. Roman Ruiz con motivo de celebrarse las bodas de oro de la facultad de medicina de Ica.

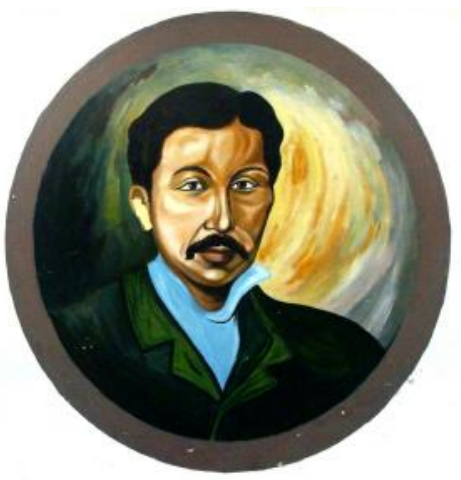

Figura 1. Retrato de Daniel Alcides Carrión, extraido del antiguo mural de la fachada de la facultad de medicina de Ica.

- Programa de segunda especialización (1968).

- En 1984 se acogen a la nueva disposición del residentado médico.

- Se inician los cursos de post grado en el 2001, con la coordinación y colaboración del Dr. Jorge Ybaseta Medina se realiza el primer curso nacional sobre la obstetricia basada en evidencias. Docentes de la Universidad Peruana Cayetano Heredia desarrollaron cursos de metodología de la investigación, epidemiología de campo, bioética, etc. Por intermedio del Dr. Teófilo Jara Jefe de la Unidad de cuidados intensivos maternos del Instituto Materno Perinatal se consigue el primer convenio que permitió la rotación del Dr. Jorge Ybaseta en la UCI Materno y Colposcopia.

- Participación en las Jornadas Clínicas quirúrgicas del Sur Medio todos los años.

- Formación de la Tuna Estudiantil (1980). 
- Sociedad Científica de Estudiante de 2013.

Medicina (SOCEMI) obtienen primer puesto nacional y extranjero.

Actividades desarrolladas por las bodas de

- Formación del Comité Operativo de Emergencias estudiantil (COE).

Patronato de apoyo a la Facultad de Medicina

Fundado el 15 de julio de 1994, sus primeras autoridades el Dr. Caros Tinajeros, Sr. Eduardo Ghersi. En el año 2002 se reactiva el patronato con el Sr. Victor Mallma, el Dr. Carlos Arana y la Lic. Gladys Gallardo, además de mi persona.

Siendo Presidente el Dr. Feliciano Lem, el patronato se convierte en una institución con registro legal en La SUNAT. Cumple funciones de ayuda económica para la Facultad de Medicina.

Centro Médico Universitario: creado el 23 de julio de 1999, siendo director el Dr. Pilades Loza, su atención a la comunidad iqueña era con rapidez y caridad. Seria conveniente que este centro regrese a la Facultad de Medicina.

Revista Médica Panacea, bajo la dirección del Dr. Jorge Ybaseta se logra ser una importante Revista Científica del Sur del País, Indizada en importantes bibliotecas virtuales del mundo donde se publican la producción científica de nuestra Facultad dando prestigio a la Universidad San Luis Gonzaga de Ica.

\section{Acreditación}

oro de la facultad:

- Taller de diseño curricular.

- Jornada regional y macro regional a cargo de la Sociedad Cientifica de estudiantes de medicina de Ica (Socemi).

- Curso de gastroenterología pediátrica.

- Conferencia de radiología, ética, sistema nervioso.

- Primer curso "revisión de artículos de investigación"

- Deportes (varias disciplinas)

- Exposición pictórica, concierto, artes, colibrí de plata.

- Romería y campañas medicas

- Entrevistas periodísticas

- Almuerzo de promociones.

Quiero culminar este informe diciendo, que con el paso de los años, presenciamos el desarrollo y el crecimiento de la facultad de medicina; este es el momento de agradecer y no olvidarse de su alma mater, ni de sus profesores. Recordar siempre que nosotros somos el camino y para salir adelante, no debemos de olvidar que la juventud es una fuerza vigorosa tal como lo dijo Claude Bernard.

ción para poder superar las exigencias de la comisión de acreditación.

La facultad de medicina fue acreditada dos veces, previamente se realizó un arduo trabajo el cual se dividió en tareas administrativas, académicas y tareas de reconstrucción sobre todo después del terremoto (2007).

Colaboraron muchos docentes, el patronato, los estudiantes en diferentes construcciones, además del personal administrativo.

\section{Actividades en "bodas de oro"}

En el año 2012 con Resolución Decanal fui designado presidente de las bodas de oro. Inmediatamente nombramos a la Doctora Jesús Meza (secretaria), al Dr. Feliciano Lem (tesorero).

Comisiones ya designadas, sus presidentes fueron:

- Comisión científica: Dr. Chanllio.

- Comisión de actividades artísticas y culturales: Prof. Cerna.

- Comisión de deportes: Dr. Alzamora.

- comisión de coordinación: Dr. Munive.

Las actividades se programaron en dos etapas en Junio y en Octubre 2013. La ceremonia por las "bodas de oro" fue el 21 de Junio del

\section{CITA SUGERIDA}

Román-Ruíz C. Breve reseña histórica de la facultad de medicina de Ica. Rev méd panacea.2013; 3

(3):87-88. 